\title{
lce on the Moon boosts hopes for future lunar missions
}

[WASHINGTON] The apparent discovery announced last week of significant amounts of ice on the Moon may give a boost to several planned lunar missions, including a European concept for a lander funded primarily by private industry. But the announcement by the team responsible for Lunar Prospector appears unlikely to lead government space agencies to invest in lunar bases or other large, expensive undertakings in the near future.

Prospector scientists say they are "extremely certain" they have found between 10 million and 300 million metric tonnes of water mixed in with soil at the lunar poles. But others are urging caution, as the result based on reduced counts of medium-energy neutrons detected at the poles by the spacecraft's neutron spectrometer - is preliminary, based on only two weeks of data from a mission that will last a year.

Wendell Mendell, a planetary scientist and lunar expert at the NASA Johnson Space Center in Houston, warns that it may be premature to assume the signature is due only to the presence of hydrogen (and therefore water) when the technique is being used on a planetary surface for the first time. Until project scientists gain a better understanding of what other elements on the surface might produce the same effect, he says, "I'm not ready to go start counting ice cubes".

Nevertheless, advocates of lunar exploration say the news is likely to give a lift to international plans for follow-on missions. Japan's Lunar-A spacecraft, for example, scheduled to launch next February, will shoot two penetrators into the Moon's surface to

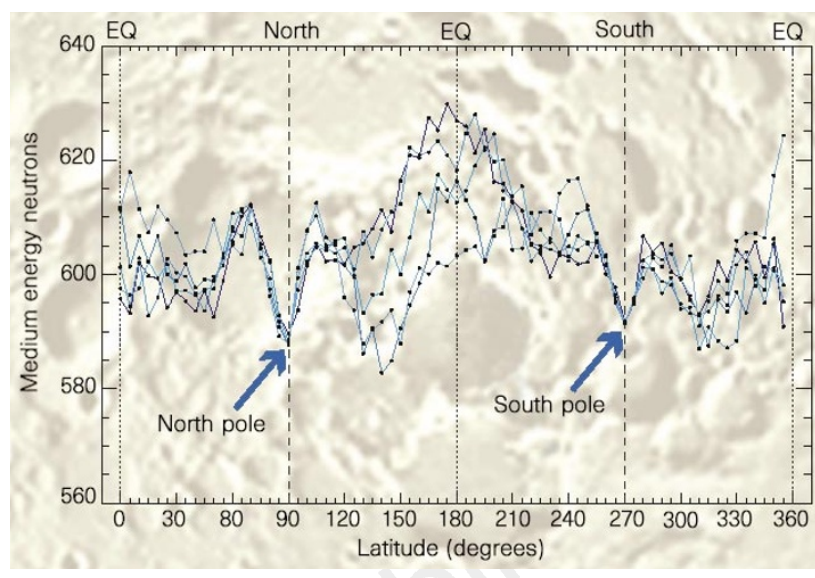

Telling evidence: early results from Prospector's Neutron Spectrometer show a drop-off in detections of medium-energy neutrons in the polar regions, where hydrogen (indicating water) has absorbed their energy. Project scientists expect the pattern to become more pronounced as more data come in.

study seismology and thermal properties.

It will be followed in 2003 by Selene (Selenological and Engineering Explorer), a joint venture of Japan's two space agencies ISAS and NASDA, which includes a lunar orbiter and lander. Money problems and the failure of the H-2A rocket last month have hampered Japan's space science programme. But the Prospector discovery may improve the missions' chances of survival.

Although Europehas repeatedly expressed an interest in lunar exploration, no mission is currently in the works. Two earlier concepts - the LEDA soft lander and an orbiter called MORO - have been shelved as too expensive. The European Space Agency's (ESA's) new SMART (Small Mission for Advanced Research and Technology) programme, which is meant to fly low-cost technology demonstration spacecraft, may provide the ideal opportunity for a small lunar orbiter

\section{Fraud claim puts German rules to test}

[MUNICH] A laboratory head and one of his technicians resigned last week from the Max Planck Institute for Plant Breeding in Cologne, following accusations of scientific misconduct involving the manipulation of experimental results. The laboratory in question works on the hormonal control of cell division in plants.

The case is the first test of the Max Planck Society's new rules governing the investigation of cases of scientific misconduct. The rules were approved by the society's senate late last year (see Nature 390, 430; 1997).

The case came to light after other scientists at the institute became suspicious of the laboratory's apparent success with a particular assay for protoplasts (cultured plant cells without their cell walls) that could not be repeated by others. They reported their suspicions to the institute's director in February.

Less than three weeks later, the institute has announced publicly - as required by the new rules - that it is embarking on an internal investigation of the laboratory's work. At least one incident of fraud in a published experiment has been confirmed, and the internal inquiry will examine earlier published work.

According to the new rules, the names of the whistleblowers and the accused will not be disclosed during the internal inquiry, which should be completed within four weeks. At that point the institute director will decide whether there is sufficient evidence to ask the society for a formal investigation by independent experts. mission. A request for proposals for SMART missions is expected to go out this spring.

More ambitious would be a concept called Euromoon 2000, which has been chosen as a candidate project for a Europe-wide celebration of the millennium (see Nature 390, 8; 1997). Although the mission is not supported by space scientists, it has a unique element that boosts its political fortunes - participation by the private sector.

ESA astronaut Wubbo Ockels, who originated the concept in 1996 and now works at the agency's ESTEC technology development centre in the Netherlands, says that threequarters of the mission's US $\$ 200$ million cost will be paid by private sponsors, including aerospace and high-technology companies, as well as Olympics-style corporate sponsors anxious to cash in on the publicity generated by a high-profile return to the Moon.

The concept calls for a small orbiter called Lunarsat to scout south pole landing sites following a launch in 2000 . The next year, a lander would be dispatched to a permanently lighted crater rim to begin setting up what Ockels calls a "robotic village" for scientific studies and technology demonstrations. Probes dropped from the lander could also be sent to explore shaded regions where Prospector has detected ice.

Sceptics dismiss the Euromoon concept as a publicity stunt, and say the viability of advertising and television revenues from a space mission is not proven. But Ockels will make his case to the ESA council this month that an investment of around $\$ 8$ million for the next phase of the project can keep it on track as it continues to draw more industry partners.

To judge by a press statement from ESA last week, the council may be inclined to grant Ockels the money. On the same day as NASA's announcement, the release outlined European plans for the Moon. At this point, the only plan in sight is Euromoon.

Tony Reichhardt 